\title{
Memorial Sloan-Kettering Cancer Center
}

National Cancer Institute

\section{Source}

National Cancer Institute. Memorial Sloan-Kettering Cancer Center. NCI Thesaurus. Code C39457.

The Memorial Sloan-Kettering Cancer Center is the world's oldest and largest private cancer center. The Center fosters a close collaboration between physicians and scientists to provide patients with the best care available while working to discover more-effective strateg ies to prevent, control, and ultimately cure cancer in the future. It became an $\mathrm{NCl}$ designated Comprehensive Cancer Center in 1971. 